\title{
Short Commons for the National Science Foundation
}

\author{
from our Special Correspondent, Washington, November
}

Ar universities throughout the United States, there is a great wave of gloom about the financial support for scientific research provided by the Federal Government. After two years during which Congress has become increasingly tough about the budget appropriations of mission-oriented agencies such as the National Aeronautics and Space Administration and agencies such as the National Science Foundation which have responsibility for a more general distribution of funds, it is not, of course, surprising that people should be uneasy about the extent to which support for science will be damaged by the competing demands of the budget of the Department of Defense, rising steadily as a result of the Vietnam war, and by the growing and serious concern for social problems in the cities and elsewhere. All this has now been brought painfully to a head by the way in which the freedom of the National Science Foundation to spend money during the current financial year-which runs from July 1 this year-has suddenly been restricted. In a long and frank discussion this week of the circumstances in which these restrictions have been imposed, Dr L. J. Haworth, director of the foundation, said quite openly that the developments in the past few weeks must necessarily cause hardship in the universities.

There is plenty of evidence of this in university departments. Although the financial year is not yet half complete, a great many grant recipients have spent a disproportionate part of their receipts from the National Science Foundation during the busy summer months. Still others, understandably and inevitably, have committed themselves to substantial expenditures between now and July 1, 1969. The salaries of research assistants obviously play an important part in the budget of many groups for the next few months. During that same period, bills will come in for important and expensive items of equipment for which orders were placed earlier in the financial year. In the circumstances, it is not surprising that several groups are hard pressed, at this late stage, to reduce their expenditure by anything between 10 and 30 per cent.

At Berkeley last week, one group leader was seeking anxiously for some way of supporting two research assistants already on the books out of a sum of money now baraly sufficient to cover the costs of equipment already ordered. Elsewhere, at the California Institute of Technology, for example, people are taking a hard line with those who write asking for places as research fellows; the best recommendation is an assurance of grant support. The future of several capital developments has also been put in hazard by recent eventsthe new linear accelerator being built in the Physics Department at Stanford University, which is designed to exploit the benefits of superconducting cavity resonators and magnets, will be equipped with a cryogenic system by the Office of Naval Research but will otherwise run out of funds some time in March next year unless the National Science Foundation can put its hands on something extra.

How has all this come about? Why is it that the
National Science Foundation is having to short-change its dependants at this late stage in the financial vear? And who is to blame-Congress, the Administration or perhaps even the NSF ? And what is the future-is the unhappy experience of the past few weeks a sign of even harsher times to come? These are only some of the gloomy questions which force themselves to the surface. Even though there are only the most sketchy answers to some of them, optimists do not exist.

There are two quite distinct causes of the present plight of the National Science Foundation. First, Congress this summer took a particularly niggardly view of the foundation's claim on public funds and trimmed its application for new appropriations by

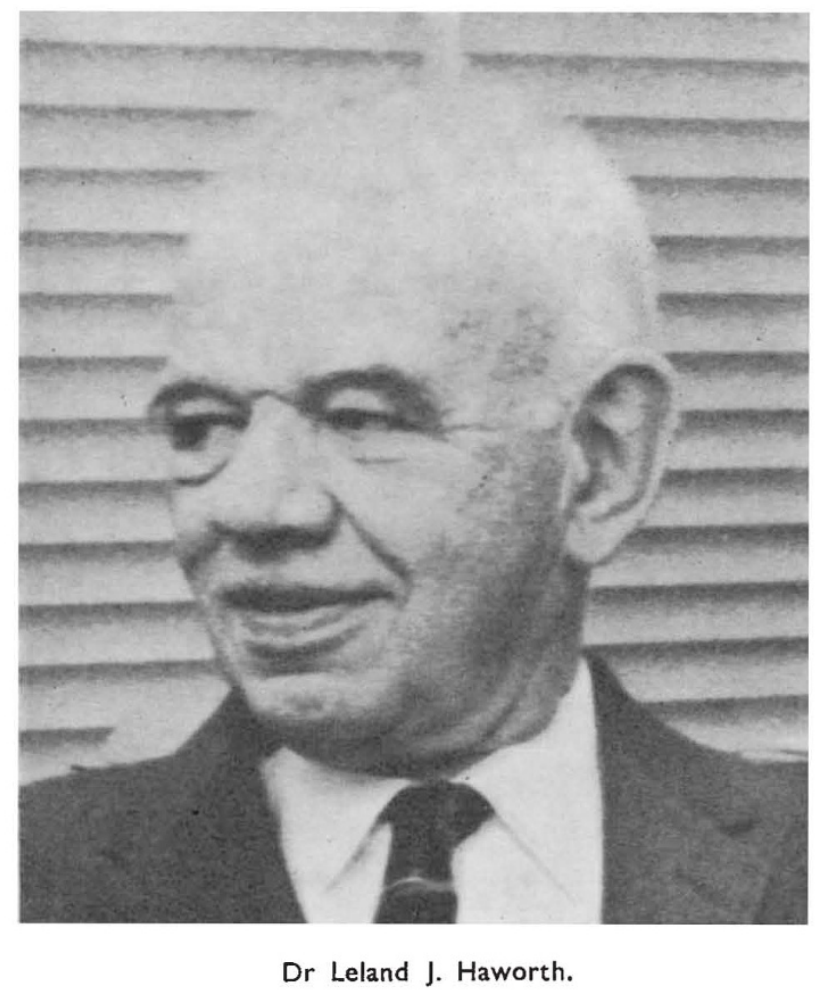

roughly 20 per cent, from $\$ 500$ million to $\$ 400$ million. This move naturally implies a severe restriction of the rate at which the foundation can commit funds to the support of new (or renewed) research programmes and other activities, and is one of the reasons for some of the despondency about the part which the foundation will be able to play in years ahead.

The most immediate difficulty springs, however, from the way in which Congress has this year decided to restrict the rate at which the Federal Government as a whole may spend money. Dr Haworth describes this decision as unprecedented. Formally, it is a part of the Revenue and Expenditure Control Act, 1968, itself a part of the deal between the Administration and Congress by means of which the latter has agreed to the 
10 per cent tax surcharge against which $\mathrm{Mr}$ Wilbur Mills and the House Ways and Means Committee has fought stoutly for a whole year. Briefly, the Adminis. tration was asked to trim $\$ 6,000$ million off its estimated expenditure of $\$ 186,000$ million.

The share of this which has fallen on the NSF is, on the face of things, comparatively modest-a mere three or four per cent of the $\$ 480$ million of expenditure during 1969 agreed with Congress earlier in the year. This expenditure has now to be held within the ceiling of $\$ 462.5$ million laid down by the Bureau of the Budget. This, however, conceals a much larger cut, for Dr Haworth says that the $\$ 480$ million was itself an underestimate of the likely expenditure during 1969 , now more accurately put at $\$ 515$ million. In other words, the foundation is being asked to reduce its total expenditures by roughly ten per cent at a time when much of the financial year is past.

Dr Haworth emphasizes that this sudden stringency has affected the NSF more than other agencies because of the way in which the foundation is at the mercy of its grant recipients. Ordinarily, it is for a recipient to decide how quickly to use up sums of money provided by the foundation. It is also understandable, he says, that many scientists to whom grants are awarded should spend a good deal of their grant soon after the award is made and then use the remainder of this money to pay running costs and salaries. Other agencies, Dr Haworth says, may be able to cushion themselves against the restrictions which the administration has been required to impose, possibly by juggling with dates for the completion of construction projects or by internal economies, but "the foundation is unique in that it cannot cope easily with such a situation", given that only three per cent of its expenditure goes on administration.

Flexibility within the foundation's budget is still further reduced because roughly 80 per cent of the expenditure in any year is related to grants made in the previous year. One difficulty is that payment for fellowships and traineeships to post-doctoral fellows and postgraduate students must be made at least a year in advance. The same is true of the foundation's plans for supporting summer institutes for the in-service training of teachers. Between them, these programmes account for 20 per cent of the foundation's expenditure. Flexibility is further diminished by the way in which the foundation is committed to long-term constructional projects undertaken with grant funds. The extent to which the foundation's hands are tied is also, according to Dr Haworth, expressed by the fact that 80 per cent of the foundation's expenditure in any year relates to obligations undertaken in previous years. This means, for example, that the foundation could only have allowed expenditures in 1969 to continue as planned if it had been prepared to reduce quite drastically the scale on which new funds were committed during 1969.

The pressure on the foundation's budget seems this year to have been made even tighter by the way in which a number of desirable projects were postponed from 1968 to 1969 , and by the general air of economy which has led grant recipients in the United States to want to use foundation funds more rapidly, and which has diminished the capacity of other Federal agencies to help with the financing of scientific research in the universities. What with the way in which the second half of each fiscal year tends to be that in which grants are made most readily, the tendency for roughly half the money spent on research grants to consist of grants for a year or more and the necessarily high proportion of these sums devoted to salaries, it is not surprising that the restrictions imposed by Congress have created an acute problem at the foundation and in the universities.

How has the foundation dealt with this ? When it first secmed that Congress would impose a ceiling on expenditure in return for the ten per cent tax surcharge, the foundation warned universities in receipt of grants that it might be difficult to pay these in full. On August 14 this year, a formal letter was sent to those universities receiving more than $\$ 50,000$ a year from the foundation suggesting ceilings for expenditure during the current fiscal year. The foundation seems first of all to have tried to anticipate how the expenditure of individual universities would have changed between 1968 and 1969 , and then to have made special allowanco for those universities committed to construction projects or other large expenditure. Keeping back a reserve fund which seems to have been about $\$ 20$ million, the foundation then set ceilings for expenditures at individual universities which seem to have entailed reductions ranging in size up to about 17 per cent.

Dr Haworth emphasizes that it would have been a gigantic task to deal individually with the 20,000 grant recipients on the foundation's books, but no doubt he has also been hoping that it would have been possible for university administrations to cushion particularly deserving grant recipients against the most severe rigours of the restrictions. He also says that it would have been extremely difficult to have embarked on discussions with roughly 800 individual universities or 20,000 grant recipients before deciding what ceilings should be imposed.

At the receiving end, of course, the foundation has been criticized not so much for the need to act quickly, ultimately the responsibility of Congress and the Bureau of the Budget, as for the way in which it has imposed the restrictions. Certainly there has been some bad feeling because responsibility for final decisions has been left with university administrations, because the several committees of the National Science Foundation have not been consulted about the principles upon which restrictions have been imposed and even because the foundation asked that injured grant recipients should not protest until 90 days had passed. Dr Haworth says that there would certainly have been no time to consult each of the 20,000 grant recipients, but he does think it may have been a "judgmental error" to have set about the job in precisely the way decided upon.

In the event, universities and research workers have not been too seriously inhibited by the foundation's request for 90 days breathing space and, indeed, early in October institutions suffering particularly from the restrictions were invited to declare themselves. Since then, the foundation has been using its reserve of funds to deal with hard cases-and, like a court of justice dealing with appeals against sentences, has actually further reduced the expenditures authorized by two of its grants. It remains to be seen how effective these measures will be, but given the political hiatus between now and the inauguration of the next Administration on January 20 , there is obviously very little outside relief to be expected. 